Article

\title{
Comparative Pathogenicity of Wildlife and Bovine Escherichia coli O157:H7 Strains in Experimentally Inoculated Neonatal Jersey Calves
}

\author{
Elizabeth M. Antaki-Zukoski ${ }^{1,2}{ }^{(D}$, Xunde Li $^{1,2}{ }^{\text {, Patricia A. Pesavento }}{ }^{3}$, Tran H. B. Nguyen ${ }^{1}$, \\ Bruce R. Hoar ${ }^{4}$ and Edward R. Atwill ${ }^{1,2, *}$ \\ 1 Department of Population Health and Reproduction, University of California, Davis, CA 95616, USA; \\ emantaki@ucdavis.edu (E.M.A.-Z.); xdli@ucdavis.edu (X.L.); tphnguyen@ucdavis.edu (T.H.B.N.) \\ 2 Western Institute for Food Safety and Security, University of California, Davis, CA 95618, USA \\ 3 Department of Pathology, Microbiology, and Immunology, University of California, Davis, CA 95616, USA; \\ papesavento@ucdavis.edu \\ 4 College of Agriculture and Natural Resources, University of Wyoming, Laramie, WY 82071, USA; \\ brucehoar@gmail.com \\ * Correspondence: ratwill@ucdavis.edu; Tel.: +1-530-754-2154
}

Received: 8 August 2018; Accepted: 12 October 2018; Published: 15 October 2018

\begin{abstract}
Shiga toxin-producing Escherichia coli, like E. coli O157:H7, are important human and animal pathogens. Naturally-acquired E. coli O157:H7 infections occur in numerous species but, particularly, cattle have been identified as a significant reservoir for human cases. E. coli O157:H7 are isolated from a number of domestic and wild animals, including rodents that share a living space with cattle. These Shiga toxin-producing E. coli O157:H7 strains can be highly virulent in humans, but little is known about the sequelae of interspecies transfer. In a group of neonatal calves, we determined the differences in colonization patterns and lesions associated with infection using either a wildlife or bovine E. coli O157:H7 strain. In calves challenged with the wildlife E. coli O157:H7 strain, the large (descending) colon was solely colonized, which differed substantially from the calves inoculated with the bovine E. coli O157:H7 strain, where the spiral colon was the principal target of infection. This study also demonstrated that while both interspecies- and intraspecies-derived E. coli O157:H7 can infect young calves, the distribution and severity differs.
\end{abstract}

Keywords: Interspecies transfer; intraspecies transfer; bovine; wildlife; Escherichia coli O157:H7

\section{Introduction}

Enterohaemorrhagic Escherichia coli comprise a group of emerging zoonotic microorganisms that can be pathogenic, particularly serotype O157:H7. In humans, Shiga toxin-producing E. coli (STEC) O157:H7 causes acute gastroenteritis, bloody diarrhea, and hemorrhagic colitis. Approximately 8\% of infected individuals can develop hemolytic uremic syndrome (HUS), which can lead to systemic complications or death. The severity of clinical sequelae in STEC E. coli O157:H7 infections is commonly linked to the expression and translocation of the bacteriophage-encoded Shiga-toxin across the gut epithelium. Sources of human infection include contaminated foods, primarily ground beef, raw milk, leafy green produce, and even waterborne transmission in rural areas [1-3].

Neonatal animals, such as calves, are the most susceptible age class for these O157:H7 infections, which cause clinical diarrhea and result in attaching/effacing (A/E) lesions which are severe enterocolitis with fibrinous exudation. Lesions are attributed in part to the attachment of bacterial-derived intimin to the intestinal epithelium. The attachment of E. coli O157:H7 to the host's microvillous border also reduces the tight junction integrity and causes malabsorption and 
maldigestion from a combination of the loss of both villous enterocytes and microvilli, resulting in villous contraction and the movement of immature crypt cells over the ulcerated surface epithelium [4,5].

Naturally-acquired E. coli O157:H7 infections occur in numerous species, but cattle have been identified as a significant reservoir for human infections, which is a particularly insidious problem when the animal is asymptomatic. E. coli O157:H7 has also been isolated from a number of other domestic and free-range (wildlife) animals, including rodents, which share space with cattle. Nielsen et al. [6] found a low prevalence of Shiga toxin-producing E. coli in wild animals living in close proximity to Danish cattle farms but isolates from a starling and a rat had identical serotypes, virulence profiles, and pulsed-field gel electrophoresis types to cattle isolates from corresponding farms, suggesting a possible role in pathogen transmission. Kilonzo et al. [7] also investigated the role that rodents may play in the spread of zoonotic microorganisms among agricultural farms. They concluded that the most abundant rodent species was the deer mouse, where Cryptosporidium spp., Giardia spp., Salmonella enterica serovars, and E. coli $\mathrm{O} 157: \mathrm{H} 7$ were isolated from trapped rodent fecal material.

To reduce the risk of E. coli O157:H7 transmission from animals to humans, its necessary to understand whether the passage of E. coli O157:H7 infections in different animals alter the bacteria's pathogenicity. Several analytical methods have been able to detect differences/similarities in the strain composition (focusing mainly on intimin types and Shiga-toxin gene profiles) of non-human animal E. coli O157:H7 isolates compared to clinical isolates that have infected humans [8]. It is still not well understood why some E. coli O157:H7 isolates "adapt" to certain intestinal environments and persist without causing disease, while others can cause a life-threatening condition. Heithoff et al. [9] investigated how particular strains of Salmonella enterica spp. emerge and express traits that result in increased virulence or hypervirulence due to passage through certain hosts and/or exposure to environmental variables. This reflects the complexity of the bacterial-host-environment interaction [8-10]. Here, we examine the disease progression in neonatal Jersey calves inoculated with strains of E. coli O157:H7 with similar virulence composition but isolated from separate animal sources. The objective was to observe lesion and colonization differences between the two E. coli O157:H7 isolates. The resultant lesions were examined and scored for intensity, distribution, and percent of intestinal tissue affected to determine the primary colonization sites of each strain.

\section{Materials and Methods}

\subsection{Standard Growth Curve of Bacterial Strains}

The wildlife E. coli O157:H7 strain was isolated in November 2009 from a deer mouse (Peromyscus maniculatus) in Monterey County, CA on a spinach produce ranch. The bovine E. coli O157:H7 strain was isolated in July 2007 from a herd of beef cattle at the University of California Sierra Foothill Research and Extension Center in Yuba County, CA. Three growth curves were made for each strain by incubating a bead of stock inoculum, taken from $-80^{\circ} \mathrm{C}$ frozen microbanks, in $150 \mathrm{~mL}$ of Brain Heart Infusion (BHI; Sigma-Aldrich, St. Louis, MO, USA) broth. Each E. coli O157:H7 solution was shaken (100 rpm) for $6 \mathrm{~h}$ at $37^{\circ} \mathrm{C}$ while checking optical density every $30 \mathrm{~min}$ with a spectrophotometer (Shimadzu, Torrance, CA, USA) at $610 \mathrm{~nm}$. Serial dilutions from $10^{-1}$ to $10^{-10}$ were made in $9 \mathrm{~mL}$ of Phosphate Buffered Saline, PBS (Sigma-Aldrich, St. Louis, MO, USA). Dilutions were spread-plated for growth on Luria-Bertani (LB) agar (Sigma-Aldrich, St. Louis, MO, USA) and incubated overnight at $37^{\circ} \mathrm{C}$. Using the number of colonies that grew from each dilution, the overall concentration at each time point was calculated. Each strain was also tested using end-point PCR (Eppendorf, Hauppauge, New York, NY, USA) for Shiga toxins, intimin (eaeA), and hemolysin A (HlyA) virulence factors (data not shown) [11]. 


\subsection{Ethics Statement}

All animal experiments were conducted under the approval by Institutional Animal Care and Use Committee (IACUC) of the University of California (UC) Davis Animal Care and Use program, AUP \#15459. Experimental procedures followed the federal guidelines outlined in the "Animal Welfare Act" and "Health Research Extension Act," where personal protective equipment for each pathogen, standard operating protocols for pathogens used, daily cleaning/observation/animal enrichment, and sedation/euthanasia/necropsy methods were described in detail for the review and approval by the committee.

\subsection{Animal Experiments}

Seven calves approximately 1-2 days old that received colostrum were purchased from an approved dairy. Each calf was housed individually in a biosafety level-II animal facility at the Teaching and Research Animal Care Services (TRACS). The calves were fed commercial milk replacer without antibiotics twice daily and provided free access to water. Bedding material was removed while pens were bleached and rinsed daily, to ensure fresh fecal collection. Upon arrival, each calf was deemed healthy by clinical examination and hematological analysis with a serum chemistry panel and Complete blood count (CBC). Additionally, each calf was tested for the presence of Cryptosporidium spp. with an acid-fast stain on individual fecal samples. In order to confirm that calves were not colonized with E. coli O157:H7, fresh fecal samples and rectoanal mucosal swabs (RAMS) were collected for three consecutive days prior to experimental inoculation with E. coli O157:H7. Ten grams of each fecal sample was measured into $100 \mathrm{~mL}$ of Tryptic Soy Broth, TSB (Sigma-Aldrich, St. Louis, MO, USA), while the RAMS were placed in $50 \mathrm{~mL}$ of TSB. The samples were incubated at $25^{\circ} \mathrm{C}$ for $2 \mathrm{~h}, 42^{\circ} \mathrm{C}$ for $8 \mathrm{~h}$ followed by immunomagnetic separation (IMS) using anti-O157 antibodies (Dynal Inc, Camarillo, CA, USA) and cultured on MacConkey II agar with sorbitol, cefixime, potassium tellurite (Becton, Dickinson, Co, Sparks, MD, USA), and Rainbow agar (Biolog, Hayward, CA, USA) for the presence of E. coli O157:H7. If any colonies were considered E. coli O157:H7 suspects, traditional PCR was performed using a set of specific primers to detect O-antigen-encoding $r f b$ regions of E. coli O157:H7 [11]. Once the calves were confirmed negative for Cryptosporidium and E. coli O157:H7 prior infections, they were placed in individual pens, separated by one pen length, and housed in a biosafety level-II facility. They were then assigned an E. coli O157:H7 inoculum strain. Throughout the experiment, gowns, gloves, and boot covers were changed between individual pens to prevent cross-contamination.

\subsection{Inoculation of Animals}

One microbank (Pro-lab, Richmond Hill, OH, USA) bead for each strain, stored at $-80{ }^{\circ} \mathrm{C}$, was placed in a $250 \mathrm{~mL}$ flask containing $150 \mathrm{~mL}$ of BHI. The flasks were incubated at $37^{\circ} \mathrm{C}$ for $6 \mathrm{~h}$, while shaking at $100 \mathrm{rpm}$. Once turbidity was observed, the flasks were placed on ice for $15 \mathrm{~min}$. The optical density was then measured at $610 \mathrm{~nm}$ with the spectrophotometer and the concentration of the stock solution was calculated by using the generated growth curve from each E. coli O157:H7 strain. From the known stock solution concentration, the inoculums were prepared for each strain in PBS. For this study, three calves were inoculated with approximately $10^{10}$ Colony forming unit (CFU) of the wildlife strain and three calves were inoculated with approximately $10^{10} \mathrm{CFU}$ of the bovine strain, leaving one calf as the negative control. Serial dilutions of the inoculum from $10^{-1}$ to $10^{-10}$ were made in $9 \mathrm{~mL}$ of PBS and plated in triplicates on LB agar for each stock solution and inoculum. After overnight incubation at $37^{\circ} \mathrm{C}$, the true concentration of each dilution was calculated. The individually-housed calves were intragastrically inoculated with their assigned E. coli O157:H7 strain with a calf gastric feeder (VetOne, MWI Veterinary Supply Co., Boise, ID, USA). Each was first given the $200 \mathrm{~mL}$ of PBS containing the bacteria and then another $200 \mathrm{~mL}$ of PBS as a wash. 


\subsection{Daily Sampling and Fecal Scoring}

Fecal samples and rectoanal mucosal swabs (RAMS) were collected at 24, 48, and $76 \mathrm{~h}$ postinoculation (p.i.). Fecal consistency was scored on a scale from 1-4, with $1=$ normal, $2=$ paste, $3=$ liquid, and $4=$ water. All of the samples were collected in the afternoon and transported back to the laboratory in a refrigerated state. The samples were processed within $24 \mathrm{~h}$ of collection.

\subsection{Analytical Assays for Detecting E. coli O157:H7}

Each $10 \mathrm{~g}$ sample and RAMS were placed in separate Whirl Pak ${ }^{\circledR}$ (eNasco, Fort Atkinson, WI, USA) bags containing $90 \mathrm{~mL}$ TSB for fecal samples and $50 \mathrm{~mL}$ TSB for RAMS, and then incubated for $2 \mathrm{~h}$ at $25^{\circ} \mathrm{C}, 8 \mathrm{~h}$ at $42{ }^{\circ} \mathrm{C}$ and held overnight at $6{ }^{\circ} \mathrm{C}$. E. coli O157:H7 was recovered using IMS and the Dynal Bead Retriever (Dynal Inc, Camarillo, CA, USA), with $50 \mu \mathrm{L}$ of washed beads streaked for isolation on Rainbow agar and another $50 \mu \mathrm{L}$ streaked for isolation on MacConkey II w/Sorbitol Agar. As performed in our laboratory, this IMS method has been shown to detect as few as 1 colony-forming unit (CFU)/10 g of calf feces Two suspect colonies per positive plate were confirmed with end-point PCR [12]. Confirmed colonies were stored at $-80{ }^{\circ} \mathrm{C}$ in Microbank vials for further analysis.

\subsection{Euthanasia and Necropsy}

One calf from each E. coli O157:H7 strain was euthanized with pentobarbital sodium (Euthasol solution) intravenously and necropsied at 24,48 , and $76 \mathrm{~h}$ post-inoculation. Intestinal sections of the esophageal groove, abomasum, duodenum, jejunum, ileum, cecum, spiral colon, proximal colon, distal colon, and rectum were collected aseptically for both bacterial culture and histopathology. Sections of pancreas, liver, mesenteric lymph node, gall bladder, lung, and kidney were also taken for both procedures. Each intestinal segment was tied with string by both ends so that the contents and the mucosa could be cultured for the presence of any colonized E. coli O157:H7. Once transported to the laboratory, one end of the tissue segment was cut and the contents were collected in a Whirl Pak bag containing $90 \mathrm{~mL}$ of TSB. The intestinal tissue was then cut longitudinally to expose the mucosa and placed in a separate Whirl Pak with $90 \mathrm{~mL}$ of TSB. The non-intestinal tissues were placed in a bag containing $50 \mathrm{~mL}$ of TSB. All TSB bags were then incubated for $2 \mathrm{~h}$ at $37{ }^{\circ} \mathrm{C}, 8 \mathrm{~h}$ at $42{ }^{\circ} \mathrm{C}$, and then held overnight at $6^{\circ} \mathrm{C}$. E. coli O157:H7 was recovered using the same method as described above. Intestinal and soft tissue sections for histopathology were placed in 10\% neutral buffered formalin, provided by the California Animal Health and Food Safety necropsy floor, and allowed to fix for a minimum of two days before trimming.

\subsection{Histopathology and Lesion Scoring}

Fixed tissues were routinely processed, embedded in paraffin, sectioned, and stained with hemotoxylin and eosin (H\&E). Histology slides were then examined for pathological changes in each of the tissue segments, which included the state of mucosa (blunted villi, ulceration, and inflammation), adherent bacteria, enumeration of goblet cells, and crypt length. Representative paraffin sections were cut and stained with either a Warthin-Starry Silver stain or Giemsa stain, to ensure that estimation of bacterial load and localization by H\&E was accurate. Additional sections stained with Periodic Acid-Schiff (PAS) stain identified the changes in goblet cell number or distribution. The percentage of total area affected was also determined by counting ten glands and calculating the ratio of affected to non-affected glands due to the E. coli O157:H7 bacteria. The percentage of glands affected and overall pathological changes (lesions) were then scored on a scale from 1 to 4 , where $1=$ intact mucosa, 2 = multifocal points of erosion, 3 = bacterial attachment to the surface of the mucosa and in the submucosa with inflammatory cells (i.e., transmigrating neutrophils and eosinophils), and 4 = severe ulceration/mucosal loss with submucosa bacteria with inflammatory cells [13]. Crypt lengths $(\mu \mathrm{m})$ were measured from proximal and distal colon tissue segments at ten random glands 
and then averaged to compare to the negative control gland lengths. The tissues from each group of calves were then ranked from most to least affected depending on the overall evaluation score [13].

\subsection{Statistical Analysis}

One-way ANOVA tests were performed with SPSS (IBM Corporation, Armonk, New York, USA) computer software on mean crypt lengths from the ten measured glands in the proximal and distal colon at each time increment for the two E. coli O157:H7 strains. Additional post hoc tests with Tukey's multiple-comparison procedure and nonparametric Bonferroni (Dunn) were performed in order to compare each mean against the negative control crypt length means. All tests were performed at a level of 0.05 .

\section{Results}

Both the wildlife and bovine E. coli O157:H7 strains encoded Shiga toxins I and II, intimin (eaeA), and hemolysin A $(H l y A)$ genes. Diarrhea progressed over three days in both groups of inoculated calves. Despite intensive pre-screening, four out of the six inoculated calves were concurrently infected with Cryptosporidium spp., which was taken into consideration during pathological evaluation and scoring. These included, calves inoculated with the wildlife E. coli O157:H7 strain euthanized at 48 and $76 \mathrm{~h}$ post-inoculation; calves inoculated with the bovine E. coli O157:H7 strain euthanized at 24 and $76 \mathrm{~h}$ post-inoculation

The uninoculated control calf used for this experiment was sacrificed and presented no clinical signs of diarrhea, no gross lesions, and no histopathological evidence of intestinal disease. In all inoculated cases, regardless of the strain of E. coli O157:H7 and time post-inoculation, the lesions associated with attached E. coli O157:H7 included mucosal attenuation, erosion, ulceration, necrosis, edema, and bacterial presence in the submucosa. These changes only occurred in the large intestinal segments. Lesions for E. coli O157:H7 have been previously described [14-16]. The group of calves inoculated with the wildlife E. coli O157:H7 strain had submucosal bacteria present in at least one segment of large intestine at all post-inoculation time points, where the calf inoculated with the bovine E. coli O157:H7 stain euthanized $76 \mathrm{~h}$ post-inoculation had submucosal bacteria present in the cecum and spiral colon sections only.

Attaching/effacing (A/E) lesion development was different among the time increments after inoculation. Lesion scores were the greatest at $76 \mathrm{~h}$ post-inoculation for both E. coli O157:H7 inoculum groups, see Figure 1. The wildlife and bovine E. coli O157:H7 inoculum groups had very different lesion distribution and severity. With the progression of time post-inoculation, the calves inoculated with the wildlife E. coli O157:H7 strain had over $20 \%$ of their large intestinal segments affected by bacterial presence and lesion development. The calf euthanized at $24 \mathrm{~h}$ post-inoculation had $40-50 \%$ of necrotic mucosa in its spiral colon and distal colon sections, with transmigrating neutrophils and multifocal bacterial attachment. This progressed to $90 \%$ spiral colon and $60 \%$ distal colon containing necrotic mucosa and crypt dilation in the calf euthanized at $76 \mathrm{~h}$ post-inoculation. Lesions progressed much more rapidly in the group inoculated with the bovine E. coli O157:H7 strain, with 75\% of necrotic mucosa and a focal area of bacterial attachment in the distal colon of the calf euthanized at $24 \mathrm{~h}$ post-inoculation. The distribution and severity of affected intestinal tissue then changed in the bovine E. coli O157:H7 inoculum group. In calves euthanized at 48 and $76 \mathrm{~h}$ post-inoculation, $90 \%$ of the spiral colon mucosa was affected by diffuse bacterial attachment to the surface and submucosa. These changes can be seen histologically in Figure 2a-f. Overall, the wildlife E. coli O157:H7 strain moderately affected the entire large intestine, while the bovine E. coli O157:H7 strain mainly colonized the spiral colon, see Figure 3. 



Figure 1. Overall lesion scores at each time increment for the wildlife E. coli O157:H7 inoculum group of calves (a). Overall lesion scores at each time increment for the bovine E. coli O157:H7 inoculum group of calves (b). (hrs) hours; (p.i.) post-inoculation.

After ANOVA and post hoc testing, mean crypt lengths in the proximal colon were not significantly different $(p=0.109)$ when each $E$. coli O157:H7 group was compared by time increments, but were significantly different $(p<0.001)$ when compared within each $E$. coli O157:H7 inoculum group. The $24 \mathrm{~h}$ post-inoculation mean crypt lengths in the wildlife and bovine E. coli O157:H7 calves were both longer when compared to the calves euthanized at $48 \mathrm{~h}$ post-inoculation, who had mean lengths of $104.3 \mu \mathrm{m}$ and $90.1 \mu \mathrm{m}$. All mean lengths were significantly longer when compared to the negative control mean, except for the calf inoculated with the bovine E. coli O157:H7 strain euthanized at $48 \mathrm{~h}$ post-inoculation. When comparing within E. coli O157:H7 inoculum groups for the distal colon, the calves inoculated with the wildlife strain had no significant differences $(p=0.287)$ in mean lengths but the calf inoculated with the bovine strain euthanized at $24 \mathrm{~h}$ post-inoculation had significantly longer crypt lengths when compared to the calves inoculated with the bovine strain euthanized at 48 and $76 \mathrm{~h}$ post-inoculation $(p=0.004, p<0.001)$. There was also a significant difference in mean lengths at 48 and $76 \mathrm{~h}$ post-inoculation when each $E$. coli $\mathrm{O} 157: \mathrm{H} 7$ group was compared by time increments $(p=0.037$ and $p=0.004$ ). For the distal colon, the negative control mean length was only significantly shorter when compared to the calf inoculated with the bovine strain euthanized at $24 \mathrm{~h}$ post-inoculation $(p<0.001)$ and the calf inoculated with the wildlife strain euthanized $48 \mathrm{~h}$ post-inoculation $(p=0.003)$, see Table 1. 


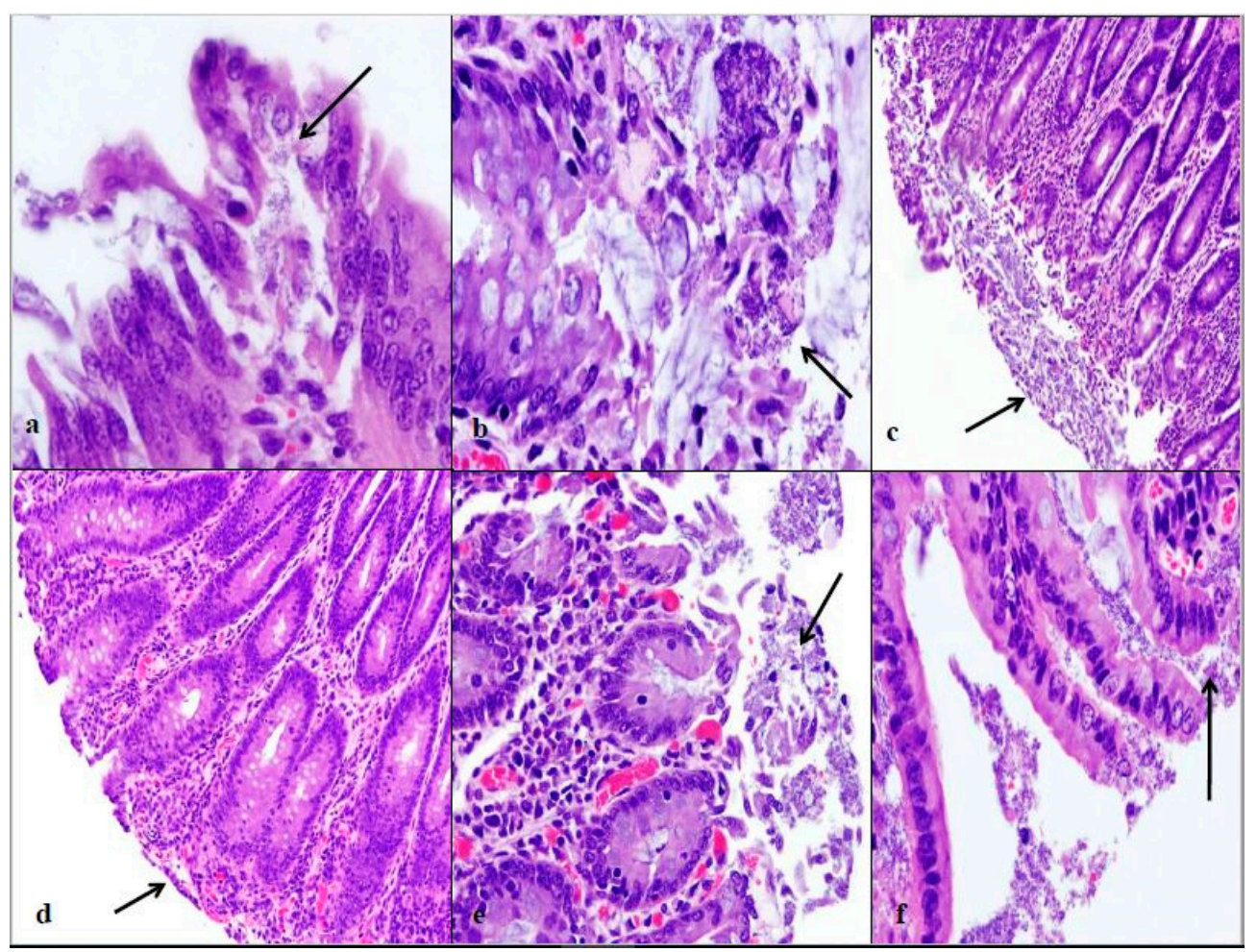

Figure 2. Intestinal lesion comparison of wildlife and bovine E. coli O157:H7 at each euthanasia time increment. Wildlife E. coli O157:H7 at $24 \mathrm{~h}$ post-inoculation contains mucosal exfoliation and attaching/effacing lesion formation in the spiral colon at 40× (a). Wildlife E. coli O157:H7 at $48 \mathrm{~h}$ post-inoculation contains edema, exfoliation of mucosa, and mucus secretion in the proximal colon at $40 \times$ (b). Wildlife E. coli O157:H7 at $76 \mathrm{~h}$ post-inoculation contains ulceration, exfoliation, and a large area of necrotic lesion in the spiral colon at $10 \times(\mathbf{c})$. Bovine E. coli O157:H7 at $24 \mathrm{~h}$ post-inoculation has attenuated and blunted mucosal epithelium in the distal colon at 10× (d). Bovine E. coli O157:H7 at $48 \mathrm{~h}$ post-inoculation contains multifocal $E$. coli bacteria and dilated crypt glands in the spiral colon at $20 \times($ e). Bovine E. coli O157:H7 at $76 \mathrm{~h}$ post-inoculation contains necrotic mucosa and submucosa E. coli bacteria in the spiral colon at $40 \times(\mathbf{f})$. The arrows indicate the pathological changes at each time point. These sections were all stained with hemotoxylin and eosin (HE).

Table 1. Comparison of mean crypt lengths $(\mu \mathrm{m})$ of ten glands post-inoculation of the (a) proximal colon and (b) distal colon at each time increment for each inoculated E. coli O157:H7 group using Tukey's multiple-comparison procedure.

\begin{tabular}{|c|c|c|}
\hline a & & \\
\hline Time (h post-inoculation) & Wildlife $(\mu \mathrm{m})$ & Bovine $(\mu \mathrm{m})$ \\
\hline 24 & $125.0^{\mathrm{A}}$ & $114.0 \mathrm{~A}, \mathrm{~B}$ \\
\hline 48 & $104.3^{\mathrm{B}, \mathrm{C}}$ & $90.1^{C}, \mathrm{D}$ \\
\hline 76 & $108.7^{\text {A, B }}$ & $106.4^{\mathrm{B}, \mathrm{C}}$ \\
\hline \multicolumn{3}{|c|}{ Negative control value $=85.6^{\mathrm{D}}$} \\
\hline \multicolumn{3}{|l|}{$b$} \\
\hline Time (h post-inoculation) & Wildlife $(\mu \mathrm{m})$ & Bovine $(\mu \mathrm{m})$ \\
\hline 24 & $96.7^{\mathrm{A}, \mathrm{B}}$ & $116.3^{\mathrm{A}}$ \\
\hline 48 & $111.4^{\mathrm{A}}$ & $90.7^{\mathrm{B}, \mathrm{C}}$ \\
\hline 76 & $101.8^{\mathrm{A}, \mathrm{B}}$ & $76.4^{\mathrm{C}}$ \\
\hline
\end{tabular}

Negative control value $=85.3^{\mathrm{B}, \mathrm{C}}$

Means without a superscript in common are statistically significantly different with a level of significance of $5 \%$ over all comparisons using Tukey's multiple-comparison procedure. 

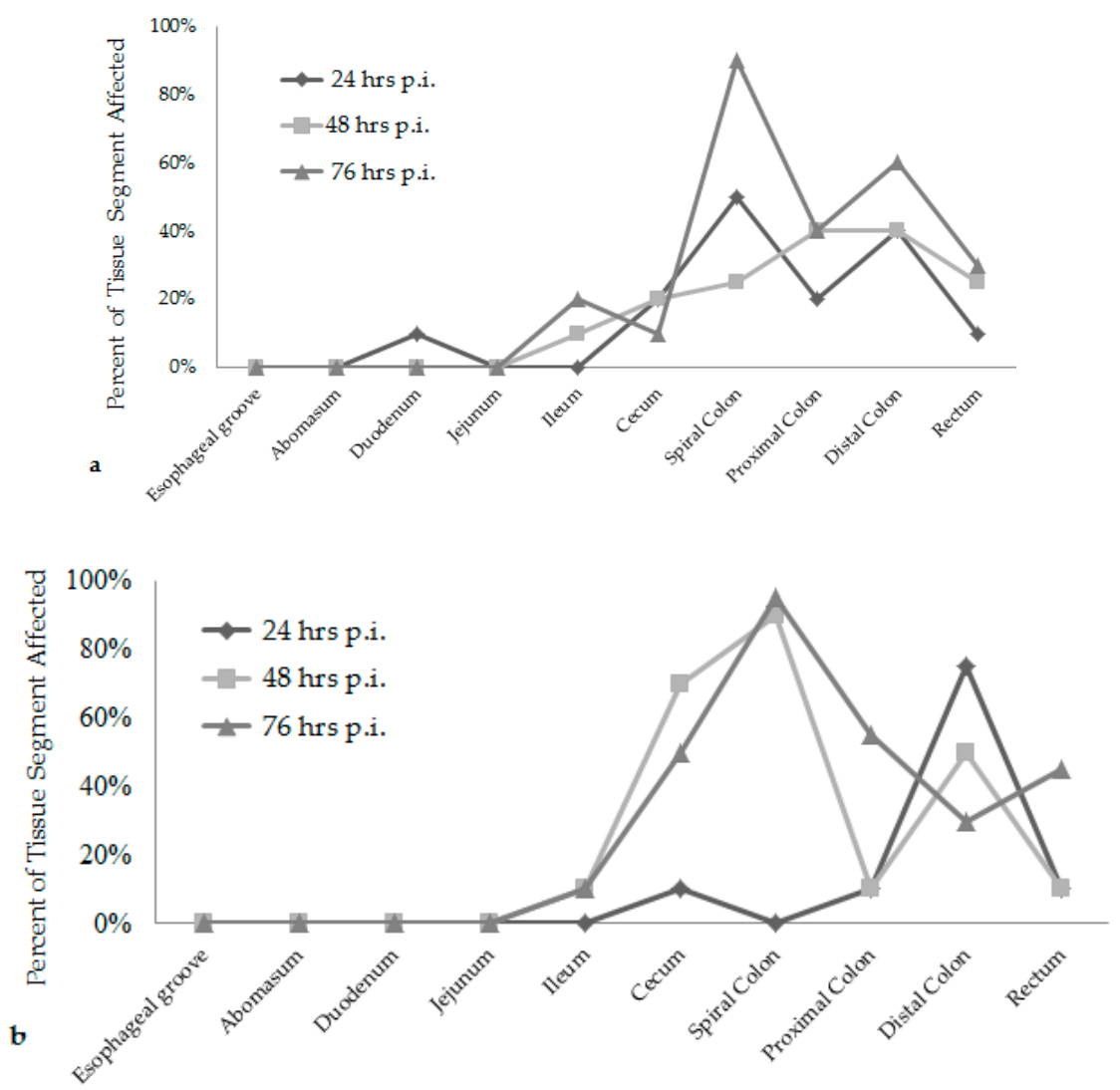

Figure 3. Percent of the total intestinal tissue segment affected at each time increment for the wildlife E. coli O157:H7 inoculum group of calves (a). Percent of the total intestinal tissue segment affected at each time increment for the bovine E. coli O157:H7 inoculum group of calves (b). (hrs) hours; (p.i.) post-inoculation.

\section{Discussion}

This study was a temporal analysis of lesion progression that compares wildlife and bovine E. coli O157:H7 strains in calves. Due to space and resources, only one calf represented each inoculum strain at the three post-inoculation time points. The high inoculum dose was to ensure that an infection would occur. Previous $\mathrm{ID}_{50}$ (infectious dose at 50\%) trials in calves with other strains of E. coli O157:H7 (data not published), showed that a high inoculum dose was needed to produce and sustain an infection in this animal model. While working with the strains in the lab, no significant differences in growth curves were seen. The main difference was the host that the strain was isolated from. It was hypothesized that the interspecies inoculation, a wildlife E. coli O157:H7 strain into calves, would result in more severe lesion development than intraspecies inoculation. Alternatively, some reports have demonstrated that the horizontal transmission of certain bacteria among animals of the same species changes the infection pattern, allowing the pathogen to adapt to the host's intestinal environment and giving it the ability to translocate to other tissues or become "hyperinfectious" [17-20]. In this study, the wildlife E. coli O157:H7 strain moderately affected the entire large intestine, colonizing the spiral colon, proximal colon, and distal colon evenly and then affecting the cecum and the rectum. This was in comparison to the bovine E. coli O157:H7 strain which primarily colonized the spiral colon, then cecum, proximal colon, and distal colon. The "adaptive" characteristic of the bovine-bovine passage in this study, where the bovine E. coli O157:H7 strain severely affected the spiral colon of the inoculated calves, could be associated with specific genes being upregulated or downregulated due to the intraspecies transmission or using an E. coli O157:H7 isolated from naturally infected cattle that produced a low infection [10]. In each of the intestinal tissues, bacteria (presumably inoculated E. coli O157:H7) were seen closely attached to the surface of the enterocytes, with many affected epithelial cells in the process 
of necrosis and moving into the intestinal lumen. Some intestinal areas were so necrotic that bacteria were seen invading the submucosa.

There was also a difference in the infection patterns of the E. coli O157:H7 strains at each time increment after inoculation. By increasing the length of time between inoculation and necropsy from $24 \mathrm{~h}$ to $76 \mathrm{~h}$, it was demonstrated that both E. coli O157:H7 strains induced extensive A/E lesions [2]. At $24 \mathrm{~h}$ post-inoculation, the wildlife strain caused more lesions throughout the large intestine compared to the bovine strain, shown in Figures 1 and 3, with lesion scores and percent of each intestinal segment affected. The bovine E. coli O157:H7 group had only small focal points of bacterial attachment in the proximal colon and rectum with intact mucosa, but the distal colon had segmentally necrotic and attenuated mucosa. There was one area of bacterial attachment, but the production of bacterial toxins might account for the 75\% mucosal destruction. At 48 and $76 \mathrm{~h}$ post-inoculation, both strains began to cause more damage in the affected sections of the large intestine. The progression of lesion formation at these two time points was assisted by the additional silver stain performed on the affected tissue sections. Both E. coli O157:H7 strains were able to form A/E lesions, but it was demonstrated that the wildlife strain started to cause damage in the large intestine within the first $24 \mathrm{~h}$ after inoculation compared to the bovine E. coli O157:H7 strain, which became more damaging around the 48 and $76 \mathrm{~h}$ mark.

Measurements of crypt lengths in the proximal and distal colon from the experimentally inoculated calves were evaluated and compared to the negative control crypt lengths to determine the severity of infection and cell turnover. In the proximal colon, all mean crypt lengths were considered significantly different in comparison with the negative control crypt length, except for the calf inoculated with the bovine E. coli O157:H7 strain euthanized at $48 \mathrm{~h}$ post-inoculation. Longer crypt lengths were observed in the $24 \mathrm{~h}$ post-inoculation wildlife and bovine E. coli O157:H7 calves when compared to the calves euthanized at $48 \mathrm{~h}$ post-inoculation. The distal colon had significant differences within the bovine E. coli O157:H7 group when the mean length of the calf euthanized at $24 \mathrm{~h}$ post-inoculation was compared to the calves euthanized at 48 and $76 \mathrm{~h}$ post-inoculation, as well as among each E. coli O157:H7 strain at 48 and $76 \mathrm{~h}$ post-inoculation time increments. The negative control mean length was only significantly different when compared to the calf inoculated with the bovine E. coli O157:H7 euthanized at $24 \mathrm{~h}$ post-inoculation and the wildlife inoculated calf euthanized at $48 \mathrm{~h}$ post-inoculation. The difference in crypt lengths of significant comparisons can be attributed to an adaptive hyperplastic response or increased cell turnover due to the mucosal injury which is being caused by the bacterial infection [21,22].

Despite pre-screening of the calves upon arrival, four out of the six inoculated calves were concurrently infected with a Cryptosporidium spp. infection present in the ileum. It is possible that the compromise or morbidity from the E. coli O157:H7 infection made the calves exquisitely sensitive to an inoculum of Cryptosporidium spp., prior exposure or contracted during the study, that was undetected by our diagnostic assays [23]. No evidence of a Cryptosporidium spp. infection was seen in the control calf.

In this study, a wildlife E. coli O157:H7 isolate from a deer mouse was demonstrated to be pathogenic and was capable of forming A/E lesions throughout the entire large intestine of neonatal calves in comparison to a bovine E. coli O157:H7 isolate that intensely affected one area of the large intestine. It was important to use this wildlife strain since wild mice can potentially carry $E$. coli O157:H7, causing possible transmission to humans when coming in contact with farm animals and produce fields [24]. Both E. coli O157:H7 strains have similar virulence capabilities to form A/E lesions but have different tissue infection patterns and severity in neonatal calves, possibly due to inter and/or intraspecies interactions with the host. Future studies will help investigate these relationships further with various inter and intraspecies hosts to determine the change in virulence patterns between various E. coli $\mathrm{O} 157: \mathrm{H7}$ isolates. 


\section{Conclusions}

Both strains of E. coli O157:H7, isolated from different animal sources, were shown to be pathogenic in this calf model, where one was more severe with regard to intestinal tissue colonization in comparison to the other. The wildlife E. coli O157:H7 strain was able to affect a wider distribution of the large intestine when compared to the bovine E. coli O157:H7 strain, which mainly affected the spiral colon. Due to the infection, crypt lengths within the proximal and distal colon were different in length when compared to the negative control, meaning that an adaptive response was occurring due to the mucosal injury. It was significant to show the lesion progression and differences in the pathogenesis of both E. coli O157:H7 strains over a $76 \mathrm{~h}$ period since E. coli O157:H7 can be easily transmitted to a wide range of hosts. Even though clinical signs may be slight or not present, infections can still be occurring, leading to potential contamination.

Author Contributions: Conceptualization, X.L, E.R.A., E.M.A.-Z., and P.A.P.; Methodology, X.L., E.M.A.-Z., and T.H.B.N.; Software, E.M.A.-Z.; Validation, X.L., E.M.A.-Z., and T.H.B.N.; Formal Analysis, E.M.A.-Z. and P.A.P.; Investigation, X.L., E.M.A.-Z., T.H.B.N., and B.R.H.; Resources, X.L., E.R.A., E.M.A.-Z., P.A.P., and B.R.H.; Data Curation, E.M.A.-Z. and T.H.B.N.; Writing-Original Draft Preparation, E.M.A.-Z.; Writing-Review \& Editing, X.L., E.R.A., E.M.A.-Z., P.A.P., and B.R.H.; Supervision, E.R.A. and X.L.; Project Administration, E.R.A.; Funding Acquisition, E.R.A. and X.L.

Funding: Support for this research was provided to the Western Center for Food Safety contract U01-003-572 from the U.S. Food and Drug Administration. Its contents are solely the responsibility of the authors and do not necessarily represent the official views of the FDA.

Acknowledgments: The authors are grateful to the Teaching and Research Animal Care Services for their assistance on the purchasing, care, and transportation of the animals used for this experiment. The authors would also like to thank the California Animal Health and Food Safety, University of California, Davis, for their necropsy floor and their overall assistance. In addition, the authors would like to acknowledge Melissa Partyka in Population Health and Reproduction, University of California, Davis, and Calvin Lee at the Western Institute for Food Safety and Security, University of California, Davis, for their help in editing the figures for publication.

Conflicts of Interest: The authors declare no conflict of interest. The funders had no role in the design of the study; in the collection, analyses, or interpretation of data; in the writing of the manuscript, and in the decision to publish the results.

\section{References}

1. Centers for Disease Control and Prevention. Investigation Update: Multistate Outbreak of E. coli O157:H7 Linked to Romaine Lettuce. Available online: https:/ / www.cdc.gov/ecoli/2018/o157h7-04-18/index.html (accessed on 14 October 2018).

2. Dean-Nystrom, E.A.; Bosworth, B.T.; Moon, H.W.; O’Brien, A.D. Escherichia coli O157:H7 requires intimin for enteropathogenicity in calves. Infect Immun. 1998, 66, 4560-4563. [PubMed]

3. Phillips, A.D.; Navabpour, S.; Hicks, S.; Dougan, G.; Wallis, T.; Frankel, G. Enterohaemorrhagic Escherichia coli O157:H7 target Peyer's patches in humans and cause attaching/effacing lesions in both human and bovine intestine. Gut 2000, 47, 377-381. [CrossRef] [PubMed]

4. Kumar, V.; Abbas, A.; Fausto, N. Robbins and Cotran Pathogenic Basis of Disease, 7th ed.; Elsevier Inc.: Philadelphia, PA, USA, 2005; pp. 828-835.

5. McGavin, D.M.; Zachary, J.F. Pathogenic Basis of Veterinary Disease, 4th ed.; Mosby Inc.: St. Louis, MO, USA, 2007; pp. 342-363. ISBN 978-0-323-02870-7.

6. Nielsen, E.M.; Skov, M.N.; Madsen, J.J.; Lodal, J.; Jespersen, J.B.; Baggesen, D.L. Verocytotoxin-producing Escherichia coli in wild birds and rodents in close proximity to farms. Appl. Environ. Microbiol. 2004, 70, 6944-6947. [CrossRef] [PubMed]

7. Kilonzo, C.; Li, X.; Vivas, E.J.; Jay-Russell, M.T.; Fernandez, K.L.; Atwill, E.R. Fecal shedding of zoonotic food-borne pathogens by wild rodents in a major agricultural region of the central California coast. Appl. Environ. Microbiol. 2013, 79, 6337-6344. [CrossRef] [PubMed]

8. Mora, A.; López, C.; Dhabi, G.; López-Beceiro, A.M.; Fidalgo, L.E.; Díaz, E.A.; Martínez-Carrasco, C.; Mamani, R.; Herrera, A.; Blanco, J.E.; et al. Seropathotypes, phylogroups, Stx subtypes and intimin types of Shiga toxin-producing Escherichia coli strains from wildlife animals with the same characteristics as human pathogenic isolates. Appl. Environ. Microbiol. 2012, 78, 2578-2585. [CrossRef] [PubMed] 
9. Heithoff, D.M.; Shimp, W.R.; House, J.K.; Xie, Y.; Weimer, B.C.; Sinsheimer, R.L.; Mahan, M.J. Intraspecies variation in the emergence of hyperinfectious bacterial strains in nature. PLoS Pathog. 2012, 8, e1002647. [CrossRef] [PubMed]

10. Renter, D.G.; Morris, G.J., Jr.; Sargeant, J.M.; Hungerford, L.L.; Berezowski, J.; Ngo, T.; Williams, K.; Acheson, D.W.K. Prevalence, risk factors, O serogroups, and virulence profiles of Shiga toxin-producing bacteria from cattle production environments. J. Food Prot. 2005, 68, 1556-1565. [CrossRef] [PubMed]

11. Philpott, D.; Ebel, F. Methods in Molecular Medicine: E. coli-Shiga Toxin Methods and Protocols; Humana Press Inc.: Totowa, NJ, USA, 2003; ISBN 978-1-59259-316-3.

12. Paton, J.C.; Paton, A.W. E. coli. Methods in Molecular Medicine ${ }^{\mathrm{TM}}$. In Methods for Detection of STEC in Humans; Philpott, D., Ebel, F., Eds.; Humana Press Inc.: Totowa, NJ, USA, 2003; Volume 73, pp. 9-26. ISBN 978-0-89603-939-1.

13. Shigeno, T.; Akamatsu, T.; Fujimori, K.; Nakatsuji, Y.; Nagata, A. The clinical significance of colonoscopy in hemorrhagic colitis due to enterohemorrhagic Escherichia coli O157:H7 infection. Endoscopy 2002, 34, 311-314. [CrossRef] [PubMed]

14. Cray, W.C.; Moon, H.W. Experimental infection of calves and adult cattle with Escherichia coli O157:H7. Appl. Environ. Microbiol. 1995, 61, 1586-1590. [PubMed]

15. Dean-Nystrom, E.A.; Bowsworth, B.T.; Cray, W.C., Jr.; Moon, H.W. Pathogenicity of Escherichia coli O157:H7 in the intestines of neonatal calves. Infect. Immun. 1997, 65, 1842-1848. [PubMed]

16. Dean-Nystrom, E.A.; Melton-Celsa, A.R.; Pohlenz, J.F.L.; Moon, H.W.; O’Brien, A.D. Comparative pathogenicity of Escherichia coli O157:H7 and intimin-negative non-O157 Shiga toxin-producing E. coli strains in neonatal pigs. Infect. Immun. 2003, 71, 6526-6533. [CrossRef] [PubMed]

17. Besser, T.E.; Richards, B.L.; Rice, D.H.; Hancock, D.D. Escherichia coli O157:H7 infection of calves: infectious dose and direct contact transmission. Epidemiol. Infect. 2001, 127, 555-560. [CrossRef] [PubMed]

18. Fernandez-Brando, R.J.; Miliwebsky, E.; Mejías, M.P.; Baschkier, A.; Panek, C.A.; Abrey-Recalde, M.J.; Cabrera, G.; Ramos, M.V.; Rivas, M.; Palermo, M.S. Shiga toxin-producing Escherichia coli O157:H7 shows an increased pathogenicity in mice after the passage through the gastrointestinal tract of the same host. J. Med. Microbiol. 2012, 61, 852-859. [CrossRef] [PubMed]

19. Merrell, S.D.; Butler, S.M.; Qadri, F.; Dolganov, N.A.; Alam, A.; Cohen, M.B.; Calderwood, S.B.; Schoolnik, .K.; Camilli, A. Host-induced epidemic spread of the cholera bacterium. Nature 2002, 417, 642-645. [CrossRef] [PubMed]

20. Wiles, S.; Dougan, G.; Frankel, G. Emergence of a 'hyperinfectious' bacterial state after passage of Citrobacter rodentium through the host gastrointestinal tract. Cell Microbiol. 2005, 7, 1163-1172. [CrossRef] [PubMed]

21. Coutinho, B.P.; Oriá, R.B.; Vieira, C.M.G.; Sevilleja, J.E.A.D.; Warren, C.A.; Maciel, J.G.; Thompson, M.R.; Pinkerton, R.C.; Lima, A.A.M.; Guerrant, R.J. Cryptosporidium infection causes undernutrition and, conversely, weaning undernutrition intensifies infection. J. Parasitol. 2008, 94, 1225-1232. [CrossRef] [PubMed]

22. Savkovic, S.D.; Villanueva, J.; Turner, J.R.; Matkowskyj, K.A.; Hecht, G. Mouse model of enteropathogenic Escherichia coli infection. Infect. Immun. 2005, 73, 1161-1170. [CrossRef] [PubMed]

23. Lass, S.; Hudson, P.J.; Thakar, J.; Saric, J.; Harvill, E.; Albert, R.; Perkins, S.E. Generating super-shedders: co-infection increases bacterial load and egg production of a gastrointestinal helminth. J. R. Soc. Interface 2012, 10. [CrossRef] [PubMed]

24. Brando, R.J.F.; Miliwebsky, E.; Bentancor, L.; Deza, N.; Baschkier, A.; Ramos, M.V.; Fernández, G.C.; Meiss, R.; Rivas, M.; Palermo, M.S. Renal damage and death in weaned mice after oral infection with Shiga toxin 2-producing Escherichia coli strains. J. Clin. Exp. Immunol. 2008, 153, 297-306. [CrossRef] [PubMed]

(C) 2018 by the authors. Licensee MDPI, Basel, Switzerland. This article is an open access article distributed under the terms and conditions of the Creative Commons Attribution (CC BY) license (http://creativecommons.org/licenses/by/4.0/). 